\title{
Determinants of non-compliance with short term antibiotic regimens
}

\author{
JILL COCKBURN, ROBERT W GIBBERD, ALEXANDER L REID, \\ ROBERT W SANSON-FISHER
}

\begin{abstract}
The contribution of doctor, patient, and consultation interaction patterns to compliance with antibiotic treatment was examined in 233 adult patients seen in general practice. Twelve variables were shown to discriminate between compliers and non-compliers. Discriminating variables relating to patients included health state, employment state, knowledge of tablet, and perception of anxiety level, difficulty in complying, and their observed anger, distance, and assertiveness in the consultation. Discriminating variables relating to doctors included provision of advice on duration of treatment, complexity of dosage schedule, age of doctor, and number of years in practice. For the most part these results confirmed previous research.

It is concluded that the doctor should consider both the dosage schedule and the patient's daily routine when prescribing antibiotic tablets. Advice on how to take the tablets should be given in specific rather than general terms. The significant effect of the age of the doctor and the years spent in practice has not been found in previous work. This finding may reflect differences in
\end{abstract}

Faculty of Medicine, University of Newcastle, 2308, NSW, Australia JILL COCKBURN, PHD, research associate

ALEXANDER L REID, MB, FRACGP, associate professor of general practice ROBERT W SANSON-FISHER, MPSYC, PHD, professor of behavioural science in relation to medicine

Faculty of Mathematics, University of Newcastle, NSW, Australia ROBERT W GIBBERD, PHD, associate professor, department of statistics

Correspondence to: Professor Sanson-Fisher. behaviour between younger doctors and their patients. This difference was not detected in the observation of consultation events.

\section{Introduction}

Adherence to treatment is essential for most successful medical treatments, and non-compliance is therefore perceived as a serious medical problem.' Though the operational definition of noncompliance varies across investigations, reviewers appear to agree that some $30 \%$ of patients in most studies fail to follow advice. ${ }^{23}$ The potential implications of this high rate of non-compliance have led to various explanatory factors being suggested as possible determinants of compliance with medical treatments. Within the sphere of patient characteristics and variables relating to illness sociodemographic factors, patient knowledge, satisfaction and health beliefs, type of illness, health state, and patients' perceived improvement in their condition after treatment have been studied. Several studies have shown a relation between some of these variables and compliance, ${ }^{49}$ whereas others have found no relation. ${ }^{10-14}$

The doctor also has a potentially important influence on compliance by virtue of his or her determination of various influences, including the acutal treatment regimen. For example, the complexity of the regimen, as indicated by the frequency of dose, number of tablets prescribed daily, and length of time for which the treatment is prescribed, has been shown to be negatively related to compliance. ${ }^{15} 16$ It has been suggested that the attitudes a doctor has towards drug treatment and patient care are also important and that patients are more likely to take medicines if the doctor believes in their efficacy. ${ }^{17}$

Though the relationship between the physician and the patient is 
widely assumed to affect compliance, few studies have specifically examined the dynamics of the relationship and its effect on taking medicines. As a result, relatively little is known about the types and components of interactions which enhance compliance.

Currently no single explanatory factor can satisfactorily explain all the variance associated with non-compliance. This study aimed at examining the predictive value of several variables which previous research has identified as being associated with noncompliance. The study focused on compliance of adult patients seen in general practice with short term prescriptions of antibiotics.

\section{Study setting, design, and method}

\section{SETTING AND DESIGN}

The data are part of a large scale direct observational study which examined the processes and outcomes of consultations in the surgeries of randomly selected general practitioners. The flow chart shows the method of data collection. Consecutive adult patients were approached in the waiting

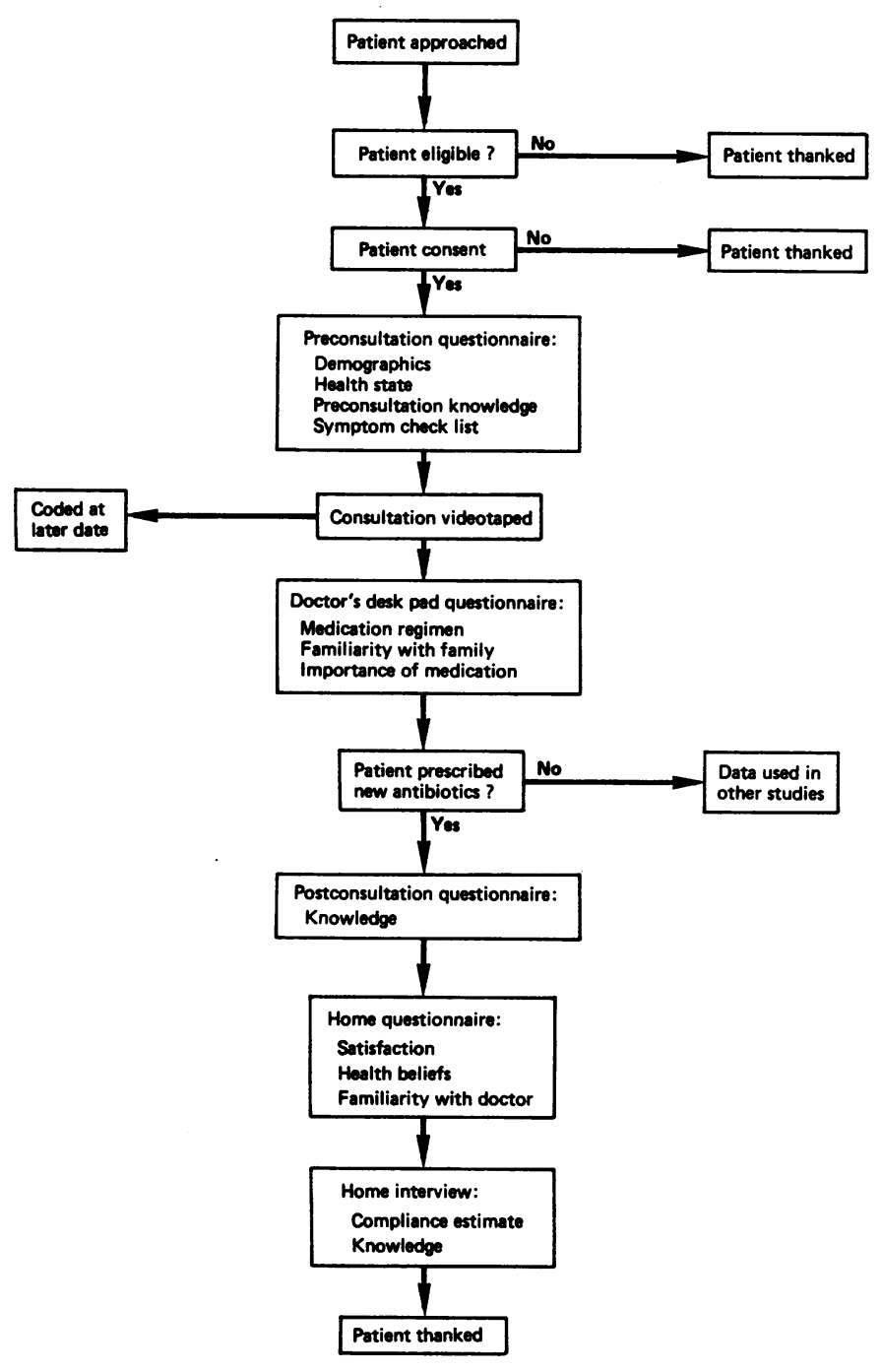

Flow chart of method of data collection.

rooms of each of the participating general practitioners before consultation. Criteria for inclusion in the sample were that the patient was 18 years of age or older, able to read and write English, and not too ill or in too much pain to complete questionnaires. After the consultation, which was videotaped, we determined whether a new course of antibiotic tablets had been prescribed (a prescription was defined as "new" if it was not a continuation of a course of tablets which had been taken the previous week). Patients receiving new prescriptions were scheduled for home interview one day before completing the course of tablets. Patients were told that the purpose of the interview was to collect more information for the study on doctor-patient relationships. At no time was compliance mentioned as a topic of interest.

At the home interview details of the patients' degree of compliance, the conditions which surrounded this behaviour, and the types of errors which had occurred were documented. A count was also made of the tablets which remained in the bottle. In addition, in a subsample of patients a urine sample was obtained to monitor the validity of the pill count. ${ }^{18}$

\section{SOURCES OF DATA}

Patient variables-Data on patient demographic variables were obtained by questionnaire before the consultations. Patient satisfaction with the care given in the consultation was obtained by a questionnaire completed at home after the consultation. The questionnaire on satisfaction contained two subscales measuring satisfaction with the interpersonal aspects of the consultation and the information given in the consultation. Further details of the construction and validation of this questionnaire are given elsewhere. ${ }^{18}$ The health beliefs of patients were measured by a four scale questionnaire taken home by patients and returned by post. Details of the construction and validation of the questionnaire are also given elsewhere. ${ }^{19}$ The patient's knowledge of the presenting illness was measured before he or she saw the doctor. After the consultation patients were asked about their knowledge of the diagnosis and of the prescribed treatment. At the home interview patients were again asked if they knew the name and dosage schedule of the antibiotic.

Illness variables-Doctors completed a short "desk pad" questionnaire after the consultation with each patient, detailing the active diagnoses and whether the problems were new or continuing. Diagnoses were later coded using the International Classification of Health Problems in Primary Care. ${ }^{20}$ Health state was measured by a scale adapted from Mushlin and Appel. ${ }^{21}$ Items in the scale addressed the amount and strength of pain, level of anxiety, limitation of normal activities, and improvement of condition. Responses for these items were aggregated to give a score on the overall heath state index. Patients were also asked at the home interview the degree to which their condition had improved.

Characteristics of antibiotic regimen-Details of the name and dosage schedules of antibiotics, as provided by the practitioner using the desk pad questionnaire, were classified into groups according to the number of times a day that the medication was to be taken. Patients were asked at the home interview about the difficulty of fitting the tablets into the daily routine and about any side effects experienced. Duration of treatment was determined by counting the number of days between the consultation and the home interview.

General practitioner characteristics-The doctors' attitudes towards patient care were measured by a 21 item questionnaire containing seven subscales. Details of construction and validation of the questionnaire are given elsewhere. ${ }^{22}$ Demographic details and details of the organisation of the general practice were also obtained by this questionnaire. On the desk pad questionnaire the general practitioner was asked to judge on a five point scale how important it was for the patient to take the medication as prescribed.

Doctor-patient interaction-Measures which described the quality of information transfer, the degree of mutuality between patient and doctor, and the affect of the consultation were obtained from the reliable coding of videotapes by trained observers. These measures were obtained by coding doctor and patient verbalisations, rating affect, and documenting treatment instructions and compliance aiding strategies used by the doctor. A full description of the scale used to code the interaction and the interactional variables derived from the coding to describe the interaction are given elsewhere. ${ }^{18}$

Measurement of non-compliance-The discrepancy between the number of tablets which should have been taken at the time of the home interview and that actually taken (obtained from the pill count) was calculated from the formula [(No of tablets that should have been taken-No actually taken)/No that should have been taken] $\times 100$. This gives a score which expresses the percentage deviation from the dose which should have been taken at the time of the home interview. A patient was classified as non-compliant if he or she had deviated by more than $20 \%$ of the prescribed dose at this time. This cut off point was derived from a validation study described elsewhere. ${ }^{18}$ Briefly, a standard chromatographic assay was used to determine the presence or absence of antibiotic in urine from a subsample of patients at the time of the home interview. The assay result was used as a gold standard of patient noncompliance. This was compared with the estimate of compliance obtained from the pill count in these patients in order to determine a cut off point in the pill count distribution which gave the most accurate reflection of true non-compliance. The point at which the patient deviated by more than $20 \%$ from the prescribed dose gave a sensitivity for detecting true non-compliance 
TABLE I-Demographic characteristics of patient sample $(n=233)$. Except where stated otherwise, figures are numbers (percentages) of patients

\begin{tabular}{lc|lc}
\hline Characteristics & & Characteristics & \\
\hline Mean age (years)(SD) & $36 \cdot 5(15 \cdot 2)$ & Tertiary education: & \\
Sex ratio(M:F) & $2: 3$ & None & $208(90)$ \\
Country of birth: & $201(89)$ & Degree or diploma & $23(10)$ \\
Australia & $20(9)$ & Employment state: & $140(61)$ \\
United Kingdom & $5(2)$ & Unemployed & $12(5)$ \\
Other & $56(24)$ & Homeduties & $51(22)$ \\
Marital state: & $149(64)$ & Student & $6(3)$ \\
Single & $6(3)$ & Retired & $13(6)$ \\
Married & $21(9)$ & Invalid & $6(3)$ \\
Widowed & & & \\
Divorced & $14(6)$ & & \\
Secondary education: & $175(75)$ & & \\
None & $44(19)$ & & \\
Lower & & \\
Upper & & & \\
\hline
\end{tabular}

^Because of missing data there are fewer than 233 patients for some variables.

TABLE II-Distribution of illnesses in compliance sample prescribed antibiotics

\begin{tabular}{lc}
\hline & $\begin{array}{c}\text { No (\%) of } \\
\text { patients }\end{array}$ \\
\hline Diseases of respiratory system & $147(63)$ \\
Diseases of renal system & $21(9)$ \\
Diseases of ear and nose & $21(9)$ \\
Diseases of skin & $21(9)$ \\
Diseases of female genitalia & $9(4)$ \\
Diseases of digestive system & $5(2)$ \\
Unspecified viral infections & $7(3)$ \\
Dental conditions & $2(1)$ \\
\hline
\end{tabular}

$\mathrm{p}<0.05$ were entered into a stepwise logistic regression. This analysis determines the strength of that association while controlling for the effects of other predictor variables. ${ }^{23}$ For predictor variables that entered the regression equation and had $\beta$ coefficients significantly different from zero relative risks were calculated to give an estimate of the increased probability of a patient being compliant or non-compliant when the values of the predictor variables were increased.

\section{Results \\ SAMPLE}

Fifty six of 108 randomly selected general practitioners agreed to participate in the primary care study, a consent rate of $52 \%$. No significant differences were found between consenters and non-consenters in terms of demographic data, beliefs and attitudes about general practice, and certain details of practice organisation. ${ }^{24}$ Response bias as determined by the questionnaire therefore appeared to be minimal.

Patients-A total of 2337 out of 2934 eligible patients (80\%) agreed to all study procedures. Of these patients, 380 were given prescriptions for antibiotics; data on pill counts were available for 233 patients. In order to determine whether those included in the analysis were systematically different from those not included the demographic characteristics of patients with pill count data were compared with those of patients who, though prescribed antibiotics, for various reasons could not be included in the sample. No statistically significant differences were found on any of the sociodemographic variables examined. This suggests that the sample used in the study was representative of an adult general practice population for whom antibiotics are prescribed. Table I gives the demographic characteristics of participating patients. Table II shows the distribution of illnesses for which the antibiotics were prescribed. All conditions are commonly found in general practice and are conditions for which antibiotics are a standard treatment.

TABLE III-Proportions of compliers and non-compliers in categories of significant predictor variables

\begin{tabular}{|c|c|c|c|c|c|}
\hline & \multicolumn{2}{|c|}{ Compliers } & \multicolumn{2}{|c|}{ Non-compliers } & \multirow[b]{2}{*}{ Significance } \\
\hline & No & $\%$ & No & $\%$ & \\
\hline \multicolumn{6}{|l|}{ Employment state: } \\
\hline Employed & 105 & $62 \cdot 5$ & 35 & $58 \cdot 3$ & \multirow{6}{*}{$\chi^{2}=15.68 ; p=0.007$} \\
\hline Unemployed & 8 & $4 \cdot 8$ & 4 & 6.7 & \\
\hline Home duties & 36 & $21 \cdot 4$ & 15 & $25 \cdot 0$ & \\
\hline Student & 5 & 3.0 & 1 & 1.7 & \\
\hline Retired & 13 & $7 \cdot 7$ & 0 & 0 & \\
\hline Invalid & 1 & 0.6 & 5 & $8 \cdot 3$ & \\
\hline \multicolumn{6}{|l|}{ Knowledge: } \\
\hline Knew name of tablet & $\begin{array}{l}85 \\
78\end{array}$ & $\begin{array}{l}52 \cdot 1 \\
47 \cdot 9\end{array}$ & $\begin{array}{l}15 \\
44\end{array}$ & $\begin{array}{l}25 \cdot 4 \\
74 \cdot 6\end{array}$ & \multirow[t]{2}{*}{$\chi^{2}=8.95 ; p=0.003$} \\
\hline \multicolumn{5}{|l|}{ Anxiety: } & \\
\hline None & 54 & $35 \cdot 5$ & 24 & $46 \cdot 2$ & \multirow{4}{*}{$\chi^{2}=7 \cdot 56 ; p=0.05$} \\
\hline Some & 61 & $40 \cdot 1$ & 24 & $46 \cdot 2$ & \\
\hline Moderate & 29 & $19 \cdot 1$ & 2 & $3 \cdot 8$ & \\
\hline Extreme & 8 & $5 \cdot 3$ & 2 & 3.8 & \\
\hline \multicolumn{6}{|l|}{ Dosage schedule: } \\
\hline Once daily & 20 & $11 \cdot 8$ & 1 & $1 \cdot 7$ & \multirow{5}{*}{$\chi^{2}=11 \cdot 2 ; p=0.02$} \\
\hline Twice daily & 48 & $28 \cdot 4$ & 15 & $25 \cdot 0$ & \\
\hline Three times daily & 67 & 39.6 & 22 & $36 \cdot 7$ & \\
\hline Four times daily & 28 & 16.6 & 20 & $33 \cdot 3$ & \\
\hline Other & 6 & 3.6 & 2 & $3 \cdot 3$ & \\
\hline \multicolumn{6}{|l|}{ Difficulty in routine: } \\
\hline Very hard & 5 & $2 \cdot 9$ & 3 & $5 \cdot 2$ & \multirow{3}{*}{$\chi^{2}=6.03 ; p=0.05$} \\
\hline Moderately hard & 12 & $7 \cdot 1$ & 10 & $17 \cdot 2$ & \\
\hline Not at all hard & 153 & 90.0 & 45 & $77 \cdot 6$ & \\
\hline \multicolumn{6}{|l|}{ General or specific advice: } \\
\hline Specific & 47 & $72 \cdot 3$ & 11 & $47 \cdot 8$ & \multirow{2}{*}{$\chi^{2}=4.53 ; p=0.03$} \\
\hline General & 18 & $27 \cdot 7$ & 12 & $52 \cdot 2$ & \\
\hline
\end{tabular}

of $82 \%$ and a specificity for detecting true compliance of $91 \%{ }^{18}$ Twenty seven per cent of patients were classified as non-compliers at this cut off point.

\section{STATISTICAL ANALYSIS}

Initial assessment of the significance of the association between variables and compliance was by $t$ tests and $\chi^{2}$ analysis for continuous and categorical variables respectively. Variables found to be associated with compliance at

\section{ANALYSES OF ASSOCIATION}

Patient variables-Significant differences between compliers and noncompliers on patient variables were found only for employment state and knowing the name of the treatment immediately after leaving the consultation. Table III gives the proportion of compliers and non-compliers in each category of employment state. With regard to knowledge of medication, 85 $(52 \%)$ of the compliers knew the name of the antibiotic immediately after leaving the consultation, whereas only $15(25 \%)$ of the non-compliers could supply this information (table III). No significant association was found between satisfaction and compliance. Compliers and non-compliers were 
equally satisfied with both the interpersonal skills of the doctor and the information given in the consultation. Similarly, no significant differences were found between compliers and non-compliers on any of the dimensions of the health belief model measured in this study.

Illness variables-An association was found between compliance and the level of anxiety that the presenting condition was causing before the consultation (table III). Compliers also scored significantly higher on the overall health state index, perceiving their condition to be slightly worse than non-compliers (see table IV). variable of specific advice on treatment was not used because of inadequate sample size.

A total of 148 patients had complete data on the variables used in the analysis. Of these, $111(75 \%)$ were classified as compliers and $37(25 \%)$ as non-compliers. The variables in the order in which they entered the model were: years in general practice, employment state of patient, dosage schedule of the regimen, and overall health state of the patient. The goodness of fit $\chi^{2}$ of $130.67(p=0.70)$ indicates that the model fitted the data well.

TABLE IV-Mean values for compliers and non-compliers on significant continuous variables

\begin{tabular}{|c|c|c|c|c|}
\hline & Range & $\begin{array}{c}\text { Mean for } \\
\text { compliers (SD) }\end{array}$ & $\begin{array}{c}\text { Mean for } \\
\text { non-compliers (SD) }\end{array}$ & Significance \\
\hline $\begin{array}{l}\text { Health state index } \\
\text { Age of general practitioner } \\
\text { Years in general practice } \\
\text { Rating of patient anger } \\
\text { Rating of patient assertiveness } \\
\text { Rating of patient friendliness }\end{array}$ & $\begin{array}{l}4-15 \\
29-66 \\
2-35 \\
1-4 \\
4-24 \\
1-4\end{array}$ & $\begin{array}{c}12 \cdot 07(2 \cdot 6) \\
41 \cdot 09(9 \cdot 1) \\
11 \cdot 74(9 \cdot 5) \\
1 \cdot 16(0 \cdot 5) \\
17 \cdot 3(3 \cdot 2) \\
3 \cdot 3(0 \cdot 7)\end{array}$ & $\begin{array}{r}11 \cdot 08(2 \cdot 6) \\
45 \cdot 64(9 \cdot 6) \\
16 \cdot 67(9 \cdot 4) \\
1.01(0 \cdot 1) \\
16 \cdot 0(3 \cdot 4) \\
3.0(0 \cdot 7)\end{array}$ & $\begin{array}{l}t_{193}=5.93 ; \mathrm{p}=0.02 \\
t_{219}=10.42 ; \mathrm{p}=0.001 \\
t_{214}=11.56 ; \mathrm{p}=0.0008 \\
t_{193}=3.72 ; \mathrm{p}=0.05 \\
t_{193}=6.06 ; \mathrm{p}=0.01 \\
t_{193}=4.87 ; \mathrm{p}=0.03\end{array}$ \\
\hline
\end{tabular}

Characteristics of regimen-An association was found between the complexity of the regimen and compliance, a greater proportion of noncompliers receiving more complex regimens (table III). Related to this finding were patients' reports of the difficulties that they found in fitting the dosage schedule into the daily routine. A greater proportion of noncompliers expressed difficulties in this regard. None of the other characteristics of the regimen showed a significant association with compliance.

General practitioner characteristics-The doctors of compliers were younger and had not been in general practice as long as the doctors of noncompliers. Table IV gives the mean values for age and years in practice. Neither doctors' attitudes to patient care nor the importance that the general practitioner attached to the correct administration of tablets was associated with non-compliance.

Doctor-patient interactional variables-The assertiveness of patients, patient anger, and patient friendliness in the consultation were the only measures derived from the interactional analysis which showed a difference between compliers and non-compliers. Non-compliers were judged to be less assertive, less angry, and less friendly in the consultation than compliers (table IV). Of the other consultation variables measured, only one was significantly associated with compliance-namely, whether the doctor gave specific rather than general advice on how long to take the tablets.

\section{STEPWISE LOGISTIC REGRESSION}

Twelve variables from the 108 examined were found to have an association with compliance with an $\alpha$ value of $p<0.05$. With this number of comparisons it would be expected that $5-(0.05)(108)$ of these associations would be type I errors - that is, expected by chance. With this limitation in mind, the following variables which showed an association with compliance of $p<0.05$ were used in the stepwise regression: patient's employment state, patient's knowledge of medication after the consultation, patient's perceived anxiety, patient's score on the health state index, dosage schedule, perceived difficulty of compliance, number of years in general practice, degree of patient anger, and distance and assertiveness in the consultation. The two variables age of doctor and years in practice were highly correlated $(r=0.93$; $p<0.001)$; therefore, only the latter variable was used in the analysis. The

TABLE V $-\beta$ Coefficients, standard errors of $\beta$ coefficients, and relative risks of predictor variables for compliance

\begin{tabular}{lcccc}
\hline Variable & $\begin{array}{c}\beta \\
\text { Coefficient }\end{array}$ & SE & $\begin{array}{c}\text { Relative } \\
\text { risk }\end{array}$ & $\begin{array}{c}95 \% \text { Confidence } \\
\text { interval }\end{array}$ \\
\hline Years in general practice & -0.056 & 0.020 & $1.75 \star$ & 1.35 to 2.01 \\
Dosage schedule & -0.542 & 0.216 & $1.72 \downarrow$ & 1.39 to 2.14 \\
Health state index & 0.195 & 0.088 & $1.79 \neq$ & 1.38 to 2.31 \\
\hline
\end{tabular}

*Based on being in practice 10 years longer than control doctor.

tBased on increasing dosage schedule by one degree on scale of complexity-that is, increasing by one dose per day.

$\ddagger$ increasing by one dose per day. $\ddagger$ Based on increasing thro
state is getting worse.
The variables entering the logistic regression which had $\beta$ coefficients statistically significantly different from zero were the number of years the general practitioner had been in practice, the complexity of the dosage schedule, and the patient's score on the health state index (see table V). Table $\mathrm{V}$ shows the relative risks. The relative risk for years in practice indicates that if a patient saw a doctor who had been in practice for 10 years longer than a hypothetical control doctor the likelihood of that patient being non-compliant would be increased by $75 \%$. The relative risk for dosage schedule indicates that increasing the number of doses to be taken in any one day by one increased the probability of a patient being non-compliant by $72 \%$. The relative risk associated with the health state index indicates that there was an increased probability of $79 \%$ that a person would be compliant if his or her score on the health state index was to increase by three points. The value of three scale points was chosen as it is close to the standard deviation of scores on the scale.

\section{Discussion}

This study measured patient, doctor, and doctor-patient interactional variables which previous research had suggested were predictive of compliance. The results indicate that multiple factors are related to patient non-compliance.

The employment state and perceived health state of the patient may act as cues to the doctor in detecting potential non-compliance in patients prescribed antibiotics. This study indicated that people who were permanently unable to work because of long term illness or disability were more likely to be non-compliant, whereas those who perceived their present state of health to be poor because of the acute condition were more likely to be compliant. It should be noted that it is the patients' perceptions of their own present state of health which were important, not the objective clinical judgment of the doctor. Inquiries should therefore be made to determine how patients are perceiving their state of health as an aid to predicting subsequent behaviour.

The complexity of the dosage schedule was a determinant of whether or not a person was compliant. This result is consistent with previous findings. If this is taken together with the finding that patients who expressed greater difficulty in fitting the tablets into their daily routine were more likely to be non-compliant there are two important implications for clinical practice. Firstly, when considering the most appropriate treatment the dosage schedule of alternative treatments should be taken into account. When there is no therapeutic difference between two treatments the least complex should be prescribed. Secondly, when the most appropriate treatment has a complex regimen that cannot be simplified an attempt should be made to find out how well the regimen can be fitted into the patient's normal routine and an effort made to find regular events in the patient's lifestyle which can serve as reminders 
to take the tablets. Interestingly, no doctor in the study attempted to tailor the regimen for individual patients. ${ }^{18}$

The finding of a significant association between the length of time in practice and the age of the general practitioner with compliance is more difficult to explain. Years in general practice was the first variable to enter the logistic regression, and the relative risk did not change as other variables were entered. This indicates that the effect of years in general practice on compliance was independent of other variables. It therefore cannot be argued that it was due to older doctors prescribing more complex regimens or having patients who perceived their condition as being worse. Further investigation is needed to see whether younger doctors and those who have been in practice for a shorter period are behaving in different ways and using more effective motivating strategies from their older and more experienced counterparts. Such differences were not detected by the present system of interactional analysis.

This study was part of a large research project undertaken by the Newcastle Primary Care Research Group, New South Wales. We acknowledge the general practitioners and patients who participated.

\section{References}

1 Becker MH, Maiman LA, Kirscht JP, Haefner DP, Drachman RH. The health belief model and prediction of dietary compliance. A field experiment. F Health Soc Behav 1977;18:348-66.

2 Eraker SA, Kirscht JP, Becker MH. Understanding and improving patient compliance. Ann Intem Med 1984;100:258-68.

3 Gillum FR, Barsky AJ. Diagnosis and management of patient noncompliance. JAMA 1974;228:1563-7.

4 Brand F, Smith R, Brand P. Effect of economic barriers to medical care on patient's non-compliance. Public Healih Rep 1977;92:72-8.
5 Ley P. Giving information to patients. In: Eiser JR, ed. Social psychology and behavioural medicine. Chichester: John Wiley and Sons, 1983:339-74.

6 Korsch BM, Gozzi EK, Francis V. Gaps in doctor-patient communication 1. Doctor-patient interaction and patient satisfaction. Pediatrics 1968;12:855-71.

7 Becker MH, Maiman LA. Strategies for enhancing patient compliance. $f$ Community Health 1980;6:113-35.

8 Johnson D. Treatment of depression in general practice. $\mathrm{Br}$ Med $\mathcal{f}$ 1973;ii:18-20.

9 Waters WH, Gauld NV, Lenin JE. Undispensed prescriptions in a mining general practice. BrMed F 1976;i:1062-3.

10 Bartlett EE, Grayson M, Barber R, Levine DM, Golden A, Libber S. The effects of physician communication on patient satisfaction, recall and adherence. J Chronic Dis 1984;37:755-64.

11 Hulka B, Kupper L, Cassel J, Efird R, Burdette J. Medication use and misuse: physician-patient discrepancies. F Chronic Dis 1975;28:7-21.

12 Sackett DL, Haynes RB, Gibson ES, Taylor DW, Roberts RS, Johnson AL. Patient compliance with antihypertensive regimens. Patient Counselling and Healh Education 1978;1:18-21.

13 Taylor DW. A test of the health belief model in hypertension. In: Haynes RB, Taylor DW, Sackett DL, eds. Compliance in health care. Baltimore: Johns Hopkins University Press, 1979:103-9.

14 Lima J, Nazarian L, Charney E, Lahti C. Compliance with short-term antimicrobial therapy: some techniques that help. Pediatrics 1976;57:383-6.

15 Zibberflat SM. Increasing patient compliance through the applied analysis of behavior. Prev Med 1975;4:173-82.

16 Porter AMW. Drug defaulting in general medical practice. BrMed $\mathcal{Y}$ 1969;i:218-22.

17 O'Hanrahan M, O'Malley K. Compliance with drug treatment. Br Med f 1981;283:298-300.

18 Cockburn J. Variables related to antibiotic compliance in general practice patients: the application of behavioural science methodologies. Newcastle, NSW: The University of Newcastle, 1986. (Doctoral dissertation.)

19 Cockburn J, Fahey PP, Sanson-Fisher RW. The construction and validation of a questionnaire to measure the health beliefs of general practice patients. Family Practice (in press).

20 Classification committee of WONCA. ICHPCC-2. Intemational classification of health problems in primary care. Oxford: World Organisation of National Colleges, Academies and Academic Associations of General Practitioners/Family Physicians, 1979.

21 Mushlin AI, Appel EA. Testing in outcome-based equality assurance strategy in primary care. Med Care 1980;18 (suppl):5.

22 Cockburn J, Killer D, Campbell E, Sanson-Fisher RW. Measuring general practitioners' attitudes toward medical care. Family Practice (in press).

23 Armitare P. Suatistical methods in medical research. Oxford: Blackwell Scientific, 1983.

24 Cockburn J, Gordon JJ, Campbell E, Sanson-Fisher RW. Response bias in a study of general practice. Family Practice (in press).

(Accepted 24 July 1987)
Within the last few years several cases have come before the courts in which the rights of qualified as against unqualified practitioners have been in question, and we are glad to say that the courts have always been disposed to uphold and support those who are duly qualified. The last case in point, Howarth $v$. Brearley, was heard the other day before Lord Coleridge and Mr. Justice Denman, on appeal from the local court at Salford. The action was brought to recover a sum claimed as due for medical attendances and medicines supplied to the defendant; but it appeared that the attendances had been given and the medicines prescribed by an unqualified assistant, $\mathrm{Mr}$ Fitzmaurice, the qualified principal, on whose behalf the action was brought, taking himself no part in the business. On this fact being established, the judge at the trial decided against the plaintiff. This decision was upheld on appeal. Lord Coleridge, in giving judgment, said emphatically, "the attendances were really by the unqualified person, and the Act ( 21 and 22 Vic., c. 90 , sec. 32) said that no person should recover for medical services unless he was qualified and registered. The medical man whose representative sued had not himself rendered any medical servicesthat is, had not attended or prescribed; and a medical man could not recover for attendances not really rendered by him." Mr. Justice Denman added that "a qualified practitioner could not authorise an unqualified person to act for him in medical attendance. It would be a mockery to apply the doctrine of master and servant to such a case, and it would entirely defeat the intention and object of the Act." According to the report in the Times, the case of Davies $v$ Makuna, decided by the Court of Appeal in 1885, was not cited, but the judgment now given is in accord with the former one.

There, as our readers may remember, an unqualified principal had been carrying on business as a general medical practitioner, chiefly with the aid of qualified assistants, but had to some extent practised on his own account. $\mathrm{He}$ brought his action on a covenant to restrain one of his assistants from practising in the neighbourhood, where he had been employed; but failed, on the ground that the Apothecaries Act (55 George II, c. 194, sec 14) prohibits persons not duly qualified from practising as apothecaries in England or Wales, and consequently that the agreement containing the covenant was illegal, and he could not enforce it. The ground taken by the Court of appeal was broader than that now in question, for they, in effect, held that any practice as an apothecary by an unqualified person is absolutely prohibited by law. The section of the Medical Act, on the words of which Lord Coleridge and Mr. Justice Denman have now decided that charges for attendance rendered by an unqualified assistant are not recoverable, does not absolutely prohibit such attendance. But the late decision shows that if an unqualified assistant is employed, he must be employed as an assistant only, and not as a deputy.

Unqualified persons are now employed, we believe, in many cases because their services cost less than those of duly qualified assistants. If medical practitioners realise that such cheap services must be paid for by themselves, and cannot legally be charged to their patients, they may doubt whether the arrangement is likely to be a profitable one, and may be more disposed to employ assistants who have gone through the proper course of training to qualify them for the work in which they are employed. In our opinion such a result is most desirable. (British Medical foumal 1887;i:1396.)

\section{Multicultural medicine}

Animal oil-A high caste Hindu mother complained to her Irish general practitioner at her baby's six week check up, that she was very upset because she gave milk A on the advice of the English ward sister in the maternity hospital. But she subsequently learnt from her Moslem health visitor that it contained beef extract, which is taboo in the Hindu religion. She changed to milk B, which is for vegetarians, but was angry and guilty of polluting her baby's religion. She vowed never to attend that maternity hospital again. The general practitioner was sympathetic and reassuring, and he spoke to the health visitor, pleading with her to soften her advice. The health visitor told him that she could not hide the truth as it was Ramadan, and she showed him the containers of milk $A$ which contained "animal oil" and milk B which did not. Respecting her feelings the general practitioner wrote to the manufacturers, who said that animal oil is in fact cows' fat, which is added to skimmed milk to make it more like breast milk. The doctor came across a Moslem mother who read the contents which included animal oil. She was convinced that it could only be pork extract, which is taboo in the Moslem religion, and she had therefore used milk B. The Catholic midwife told her not to trust anyone and just breast feed, but she was unable to breast feed.

A doctor should never recommend a milk containing animal oil-which is beef fat-to a Hindu mother and should not hide the truth because the mother has to live with the terrible guilt feeling and cultural misunderstanding when she finds out. Patients are better informed than we may think.-BASHIR QURESHI, general practitioner, Hounslow, London. 